Results Nine (6.9\%) reported that their spouses were not aware of their serostatus, 106 (76.8\%) reported that their children were not aware of their serostatus while 59 (45.4\%) reported that their workmate were not aware of their serostatus. The patients were biassed for close relatives such as children and parents as they would not like them to be informed of their serostatus while $6.9 \%$ would not want to inform anybody. Anxiety was more prevalent among subjects who reported that their children were not aware of their serostatus. In addition, $5.4 \%$ of subjects who were of opinion that their children were not aware had anxiety morbidity, increased use of psychoactive substances and use of alcohol in a manner suggestive of dependence state.

Conclusion There is need for further studies on hesitance of HIV patients to carry along close relatives, as benefits of supports and care are lost.

\section{P4.007 FERTILITY DESIRES AMONG HIV INFECTED ADULTS AT NAIVASHA DISTRICT HOSPITAL}

doi:10.1136/sextrans-2013-051184.0906

'C W Mbuthia, ${ }^{1,2} \mathrm{~J}$ Kinuthia. 'University of Nairobi, Nairobi, Kenya; ${ }^{2}$ University of Washington, Washington, WA, United States

Background In Kenya, there are over one million adults of reproductive age living with HIV/AIDS. The unmet need for contraceptive use is sixty percent for HIV positive women. Increased availability of HAART has resulted in improved physical and sexual health, resulting in increased of risk of intended and unintended pregnancies. Understanding the fertility desires of this vulnerable group becomes paramount.

Methods Eligible HIV infected adults enrolled for care at Naivasha district hospital CCC completed a structured questionnaire after providing written consent. Chi squared tests and $\mathrm{T}$ tests were performed to determine predictors of fertility desire.

Results Three hundred men and three hundred women were recruited. Fertility desire was reported by forty-nine (sixteen percent) women and sixty-seven (twenty-four percent) men. HIV positive women were less likely to desire more children compared to HIV males. Among the demographic characteristics only the number of living children and women not on HAART were significantly associated with fertility desire. Among the two hundred and fortyeight women who did not desire fertility, one hundred and eighteen (forty-seven percent) were not using contraception. Overall, eightyfive percent of men and fifty-five percent of women were sexually active. Males (forty-six) were more sexually active than women (one hundred and twelve) among those not desiring fertility and not using contraceptives, seventy-two percent males and fifteen percent women.

Conclusions Only twenty percent of HIV infected adults' desired fertility, with men being pronatalist than women. Only about half of HIV positive women were using contraceptives despite having no fertility desire. This increases the risk of unintended pregnancies. Sexual activity was ongoing with no contraceptive use hence increasing the risks of vertical and horizontal transmission on HIV. Integration of Family planning services in CCC's should be considered.

\section{P4.008 RELATING MULTILEVEL PSYCHOSOCIAL CONSTRUCTS WITH RISKY SEX AMONG MEN WHO HAVE SEX WITH MEN (MSM) AND MALE-TO-FEMALE TRANSGENDER WOMEN (TW) IN PERU}

doi:10.1136/sextrans-2013-051184.0907

$\mathbf{1}$ A Konda, ${ }^{2} \mathrm{~A}$ Silva-Santisteban, ${ }^{3} \mathrm{~A}$ Maiorana, ${ }^{3} \mathrm{~L}$ Pollack, ${ }^{2} \mathrm{X}$ Salazar, ${ }^{2} \mathrm{C}$ F Caceres, ${ }^{3} \mathrm{~S}$ M Kegeles. 'UCLA, Lima, Peru, 'Universidad Peruana Cayetano Heredia, Lima, Peru, 3UCSF, San Francisco, CA, United States
Background Risk for HIV/STIs is high among gay men (GM) and male-to-female transgender women (TW) and understanding the underlying reasons for risk is essential for planning effective interventions. Few instruments have been developed to examine psychosocial constructs for Spanish-speaking Latin American GM/TW.

Methods We developed scales to measure psychosocial constructs and then conducted a survey to assess their association with risky sex among Peruvian GM/TW (Cronbach alphas ranged from 0.66 to 0.85). We explored constructs at the: (1) individual-level (e.g. experiences of homophobia, belief in one's capability to have safer sex), (2) social-level (e.g. social norms about safer sex, social support) and (3) community level (valuing being a part of the gay/trans community). We used student's t-tests to explore the association between these constructs and risky unprotected anal intercourse (UAI), defined as UAI in the past 2 months with non-primary partners or primary partners who are serodiscordant or serostatus unknown, non-monogamous, or who have been a primary partner for less than 6 months.

Results We surveyed $247 \mathrm{MSM} / \mathrm{TW}$ with a mean age of 31.3 (standard deviation 8.2), 200 were GM and 47 were TW. Risky UAI was reported by $18.6 \%$ of GM/TW. GM/TW reporting risky UAI also reported significantly lower social support, feeling less capable of having safer sex, having sex in challenging contexts more often, and more experiences of homophobia/transphobia. Each of these constructs were significantly associated with reporting risky UAI with a male partner (all p-values $<0.05)$. Other scales were not associated with risky UAI.

Conclusions The psychosocial scales performed well among GM/ TW and several were significantly associated with risky UAI. Constructs at the individual and social level were associated with risky UAI, suggesting that multilevel HIV/STI prevention interventions with this population may be more valuable than individual-level interventions.

\section{P4.009 DELIVERING HIV/AIDS MESSAGES ON UNPROTECTED SEX AND CONDOMS: THROUGH MOSOUES OF BANGLADESH}

doi:10.1136/sextrans-2013-051184.0908

N L Huq, F Bhuiya, S Islam Khan. ICDDR,B, Dhaka, Bangladesh

Background Within the context of imam training/orientation in Bangladesh, limited attention has been paid to imam's behaviour change for effective participation in HIV prevention interventions. This study aimed at identifying factors influencing imams in promoting or inhibiting HIV message delivery consistently through mosques.

Method Three imam groups were trained for generating effective participation in HIV prevention in Bangladesh. Both quantitative (survey and exit interview) and qualitative (observation and focus group discussion) methods were conducted among imams, Friday sermon session and mosque attendees.

Results More than $90 \%$ imams in three imam groups delivered selected HIV transmission and prevention messages. However, only $11 \%$ in Group 1, 3\% in Group 2 and none in Group 3 could articulate HIV transmission message consistently. Consistent delivery rate for HIV prevention message was $20 \%$ and $8 \%$ respectively in the first two groups. Observation and exit interview results were consistent to that of the survey result. All imams related sexual relationships outside marriage with the transmission of HIV as they felt it is consistent with religious doctrine. Despite imams' high knowledge on HIV, they were unwilling to pronounce 'unprotected sex' and 'condom'. Spiritual value of Friday sermon, presence of mixed age group of attendees and perceived reaction by community prohibited the full discussion on HIV prevention by imams.

Conclusion Strategies for generating effective participation by imams in HIV prevention interventions require extensive dialogue 
between policy makers and religious scholars. Dialogue on removing the discrepancies between risk awareness and actual knowledge in light with Quaran is likely to be more effective.

\section{P4.010 DETERMINING THE PATTERNS AND UPTAKE OF HIV TESTING AMONG YOUNG WOMEN IN TRINIDAD AND TOBAGO: IMPLICATIONS FOR HIV/AIDS POLICY}

doi:10.1136/sextrans-2013-051184.0909

B Andrews. Office of the Prime Minister, Port-of Spain, Trinidad and Tobago

Background In the Caribbean, young women are particularly at risk of being infected with HIV due to social, economic and behavioural vulnerabilities. However despite these vulnerabilties, few female young adults have been tested for HIVand know their status. Moreover there is a general paucity of studies examining the HIV testing behaviours, preferences and barriers faced among Caribbean youth. This study explores the patterns and factors associated with HIV testing behaviours among female youth aged 15-24 in three Caribbean countries: Guyana, Dominican Republic, and Haiti. The analysis is guided by Andersen's Behavioural Model.

Methods Data from population based surveys such as the Demographic and Health Surveys, the AIDS Indicator Survey are used to explore the determinants of HIV testing behaviour among young women. Independent variables were classified according to Andersen's Behavioural Model and includes: traditional predisposing variables (age, educational attainment, region of residence), vulnerable predisposing factors (age at first sex, recent sexual activity, lifetime partners, condom use, consistent condom use), predisposing variables (HIV knowledge, personal stigma attitudes, knowledge of persons living with HIV/AIDS) and enabling factors (socioeconomic status, exposure to print and non-print media, history of an STI). Statistical methods include bivariate analysis using chi-square and stepwise logistic regression modelling.

Results Proportion of youth ever tested was $17 \%$ in Haiti, $37 \%$ in Guyana and $48 \%$ in Dominican Republic. Factors associated with HIV testing were marital status, residence, age at first sex, socioeconomic status. Rural, poorer and unmarried young women were less likely to report that they were tested for HIV.

Conclusion Policies and programmes should address the structural, economic and other barriers to HIV testing faced by young women who reside in rural areas, and are poor. Messages promoting the benefits of HIV testing should target these women who are more vulnerable to HIV infection.

\section{P4.011 KNOWLEDGE OF HIV TRANSMISSION IN MALDIVIAN WOMEN: WHAT ARE ITS DETERMINANTS?}

doi:10.1136/sextrans-2013-051184.0910

${ }^{1} \mathbf{A}$ Thind, ${ }^{2} \mathrm{M}$ Aboobakur, ${ }^{2} \mathrm{~N}$ Rafiq, ${ }^{3} \mathrm{~A}$ Didi, ${ }^{1} \mathrm{M}$ Rab. 'University of Western Ontario, London, ON, Canada; ${ }^{2}$ Ministry of Health, Male, Maldives; ${ }^{3}$ UNDP, Male, Maldives

Maldives is a middle income country with a very low HIV prevalence. While the government has done a good job of raising awareness about AIDS in general, the level of appropriate HIV/AIDS related knowledge is low. The 2009 Demographic and Health Survey (DHS), which is a nationally representative survey of 7131 women, reported that while $97 \%$ of women had heard of AIDS, only $42 \%$ had a comprehensive knowledge about the disease. The level of HIV-related knowledge is a key factor in the spread of AIDS; we used the 2009 Maldives DHS to understand its determinants in women aged 15-49. Responses to questions assessing correct knowledge about modes of transmission (during pregnancy, delivery, breastfeeding, sexual intercourse, single partner, condom use, mosquito bites, and sharing food) were used to create a score, which was dichotomized by a median split to create a binary 'knowledge' (poor/good) variable. Poor/good knowledge was modelled as a function of socio-demographic (age, region, educational status, wealth, employment, and number of children), media (media exposure, internet use) and health/health system factors (use of family planning (FP), FP worker visit, health facility visit). On unadjusted analysis, older age, living in Male, being employed, number of children, media exposure, use of FP, and health facility visit were associated with having good knowledge of transmission modes. In the multivariate logistic regression, age $(\mathrm{OR}=1.04)$, higher educational level $(\mathrm{OR}=1.51)$, greater media exposure $(\mathrm{OR}=1.09)$, having a smaller number of children $(\mathrm{OR}=0.94)$, being employed $(\mathrm{OR}=1.12)$, FP use $(\mathrm{OR}=1.56)$ and health facility visit $(\mathrm{OR}=1.39)$ were statistically significant predictors of good knowledge of transmission modes. Our analysis indicates that while there are no regional or wealth related differences in level of knowledge about HIV transmission, the media and health facility visits can be used as vehicles to improve the knowledge level about HIV transmission in adult Maldivian women.

\section{P4.012 THE IMPACT OF STIGMA AND DISCRIMINATION IN MSM HIV-POSITIVE}

doi:10.1136/sextrans-2013-051184.0911

R Garcia, D G Ramos. Pontifical Catholic University of São Paulo; 05014-901, Brazil

Background Since its beginning, the Aids epidemic has established a series of social representations which impacted the daily life of men who have sex with men (MSM) living with HIV, who see themselves as doubly stigmatised due to their sexual orientation.

Methods The main objective of this study is observing the impact of stigma and discrimination in MSM living with HIV, while it specifically sets out an investigation on the possible implications HIV may bring to HIV-positive individuals as regards their perception of the disease, themselves as infected persons, their social circle and their sexual orientation, as well as the situations of vulnerability involved. The final objective is observing the different experiences of those infected before and after antiretrovirals (ARVs). This study is based on the theory of social representations, and the essentially qualitative-quantitative method used is the Discourse of the Collective Subject. The 33 participants, ranging from 20 to 60 years of age, were selected at a Centre for HIV/AIDS Treatment.

Results The results point to high rates of internalised stigma evidenced by feelings of fear, rejection, a constant state of alertness, and guilt. This perception was reflected in increased vulnerability, non-use of condoms and social isolation.

Conclusion The conclusion strongly recommends an investigation on the social, affective and sexual contexts where these individuals are inserted, while rethinking new ways of intervening in the prevention and treatment of people who live with HIV (PLWHIV).

\section{P4.013 PERCEPTIONS OF LIFE QUALITY OF PEOPLE WITH HIV/AIDS}

doi:10.1136/sextrans-2013-051184.0912

S Da Silva De Souza, B Horner Schlindwein Meirelles, D Maria Guerreiro Vieira Da Silva. Universidade Federal de Santa Catarina, Florianopolis, Brazil

A qualitative exploratory-descriptive objective "Identify the elements that influence the perception of quality of life (QOL) of people living with HIV/AIDS". Semi-structured interviews with 14 people have been carried out. The analysis resulted in four categories Quality of life: subjectivity and multidimensionality. Living with HIV/AIDS and the quality of life. Care for the living quality. Health services as enhancers of QOL. There are several factors that interfere on the QOL of those people such as: physical aspects caused by the disease, the continuation of the treatment and the 